\title{
FIRST TESTS OF SUPERTHIN, ION-IMPLANTED SILICON STRIP DETECTORS PRODUCED BY LOW-TEMPERATURE TECHNIQUE*
}

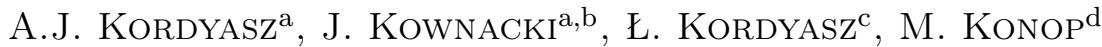

A. BednareK ${ }^{\mathrm{a}}$, M. KowAlCZYK ${ }^{\mathrm{a}, \mathrm{e}}$, J. TARASIUK $^{\mathrm{e}}$, M. KISIELIŃSKI $^{\mathrm{a}, \mathrm{b}}$

T. KOZIK ${ }^{\mathrm{f}}$, E. PiASECKI ${ }^{\mathrm{a}, \mathrm{b}}$, P. SiBCZYŃSKI ${ }^{\mathrm{b}}$, A. STOLARZ $^{\mathrm{a}}$

J. KowAlska ${ }^{\mathrm{a}}$, A. TuChOlski ${ }^{\mathrm{a}}$, J. SRebrnY ${ }^{\mathrm{a}}$

M. WolińskA-CichockA ${ }^{\mathrm{a}}$, P. NAPIORKOWSKI ${ }^{\mathrm{a}}$, J. SARNECKI ${ }^{\mathrm{g}}$

D. Lipiński ${ }^{g}, H$. Wodzińska ${ }^{g}$, M. TEOdORCZYK ${ }^{g}$, M. GAJEWSKi $^{g}$

A. ZAGOJSKI ${ }^{g}, K$ K. KRZYŻAK ${ }^{g}$

${ }^{a}$ Heavy Ion Laboratory, University of Warsaw

Pasteura 5a, 02-093 Warszawa, Poland

${ }^{b}$ National Centre for Nuclear Research, Sołtana 704-400 Otwock, Poland

${ }^{\mathrm{c}}$ Warsaw University of Technology, Faculty of Mechatronics

Institute of Micromechanics and Photonics

Department of Design of Precission Devices

Boboli 8, 02-525 Warszawa, Poland

${ }^{\mathrm{d}}$ Warsaw University of Technology, Faculty of Physics

Koszykowa 75, 00-662 Warszawa, Poland

e Institute of Experimental Physics, University of Warsaw

Pasteura 5a, 02-093 Warszawa, Poland

${ }^{\mathrm{f}}$ The M. Smoluchowski Institute of Physics, Jagiellonian University

Łojasiewicza 11, 30-348 Kraków, Poland

Insitute of Electronic Materials Technology

Wólczynska 133, 01-919 Warszawa, Poland

(Received January 18, 2016)

A new technique of producing thin strip detectors was developed. The principle of the technique is the application of a low-temperature baking process instead of high temperature annealing. This thermal treatment follows the $B^{+}$ion implantation and evaporation of $\mathrm{Al}$ as detector contacts, which are created using a single adjusted $\mathrm{Al}$ mask in form of a comb. The thickness distribution along $X$ and $Y$ directions for a thin silicon epitaxial membrane was measured by the energy loss of $\alpha$ particles from ${ }^{241} \mathrm{Am}$ $\left(\left\langle E_{\alpha}\right\rangle=5.5 \mathrm{MeV}\right)$. Preliminary tests of the first $5 \mu \mathrm{m}$ thin strip detector have been performed with $\alpha$ particles and fission fragments from ${ }^{252} \mathrm{Cf}$. The

* Presented at the XXXIV Mazurian Lakes Conference on Physics, Piaski, Poland, September 6-13, 2015. 
$\Delta E-E$ ion identification plots were created using a telescope consisting of our one thin strip of the $\Delta E$ strip detector $(5 \mu \mathrm{m}$ thick) followed by a typical $300 \mu \mathrm{m}$ Ortec E detector.

DOI:10.5506/APhysPolB.47.797

\section{Low-temperature technique of superthin strip silicon ion implanted epitaxial detectors}

Superthin silicon strip detectors are proposed to be used for construction of silicon vertex detector which allows particles energy measurements and geometrical reconstruction of all particle tracks. It can be used for investigation of low-energy multiparticle processes like decay of superheavy elements, unbound states in the Brunnian nucleus ${ }^{10} \mathrm{C}$ and for the Hoyle state of ${ }^{12} \mathrm{C}$. Up to present days, the production of superthin silicon strip detectors has not been successfully performed.

Recently, a feasible thin silicon detector technique avoiding photolithography, which is a risky operation to be performed on a fragile thin silicon membrane, has been developed, called "low-temperature technique of thin silicon ion-implanted epitaxial detectors" [1].

The aim of the present work is the extension of the new technology of thin detector preparation presented in Ref. [1] to produce superthin silicon strip detectors. The new technique to obtain thin silicon epitaxial ion-implanted detectors is illustrated in Fig. 1.

We started from a four-inch silicon epitaxial structure $n^{+}-n$, of about $300 \Omega \mathrm{cm}$ resistivity and thickness of $5 \mu \mathrm{m}$, epitaxially grown on a thick $(400 \mu \mathrm{m}),\langle 111\rangle$ oriented, low resistivity $(0.01 \Omega \mathrm{cm}) \mathrm{n}^{+}$substrate (upper part of the figure). The sample has been produced at the Institute of Electronic Materials Technology, Warsaw, Poland. Then, the substrate of the structure $\mathrm{n}^{+}-\mathrm{n}$ was removed by anodic dissolution using a HF jet [2] (middle part of the figure). The external part of the four-inch substrate close to the wafer edges is not removed in the process and acts as a mechanical support of the thin silicon epitaxial membrane. The top of the etched silicon epitaxial structure $\mathrm{n}^{+}-\mathrm{n}$ has been further covered by means of an $\mathrm{Al}$ mask in form of a comb to generate the strip structure of the superthin four-inch detector (see the bottom part of the figure) in order to select the region of the epitaxial layer for the further $50 \mathrm{keV} B^{+}$ion implantation with a fluence of $5 \times 10^{14}$ ions $/ \mathrm{cm}^{2}$. After boron implantation, final Al layers are deposited on both silicon faces, also on the front one, where the $\mathrm{Al}$ mask in form of a comb is already placed. The $B^{+}$ion implantation within the $\mathrm{Al}$ strips of the silicon epitaxial layer produces $\mathrm{p}^{+}{ }_{-} \mathrm{n}$ junctions, while the evaporated $\mathrm{Al}$ film creates the electric contact both on the $\mathrm{p}^{+}$implanted strips of the detector and on the rear wafer side (Fig. 1, lower panel). In order to activate the 
$\mathrm{p}^{+}-\mathrm{n}$ strip junctions, a final baking step was applied in air, in an oven at $160^{\circ} \mathrm{C}$ for three days. This long term, low-temperature baking process is applied instead of the standard short time (about one hour), high temperature $\left(600-950^{\circ} \mathrm{C}\right)$ post-implantation annealing at inert atmosphere.

High resistivity, thin, n-type Si epitaxial layer

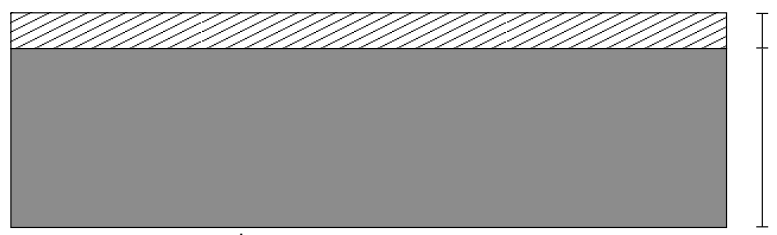

5 microns

400

microns

Low resistivity, $\mathrm{n}^{+}-$type thick Si substrate

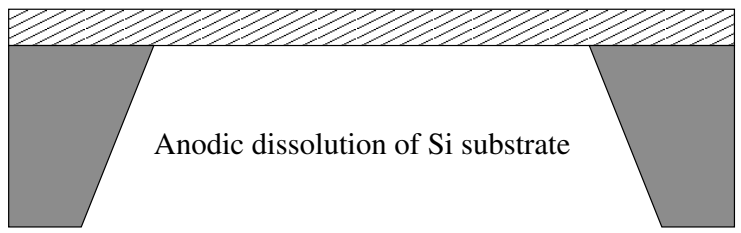

$50 \mathrm{keV}$ Boron ions implantation followed by $\mathrm{Al}$ evaporation

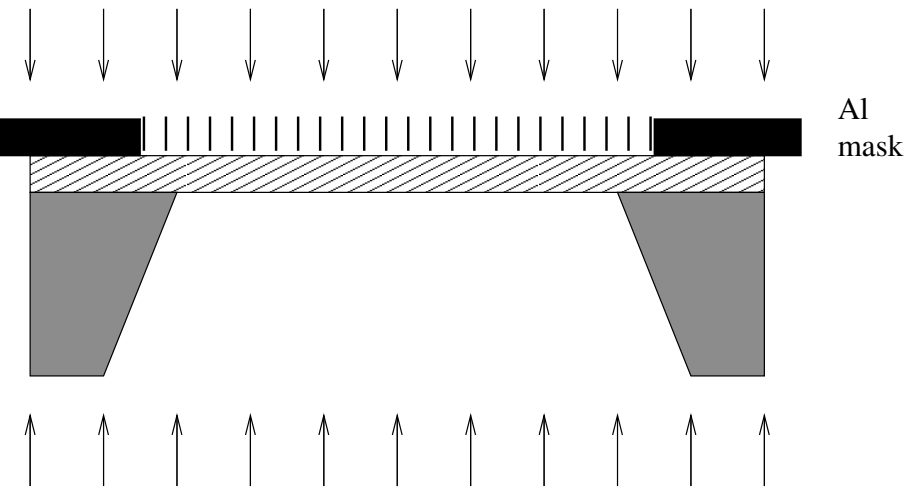

$\mathrm{Al}$ evaporation followed by long time baking of the Si detector

Fig. 1. Technology of thin silicon detector production. The starting $\mathrm{n}^{+}-\mathrm{n}$ silicon structure is shown in the upper part of the figure. The low-resistivity thick $\mathrm{n}^{+}$-type substrate is removed from the starting $\mathrm{n}^{+}-\mathrm{n}$ silicon structure (presented in the upper part of figure) by the anodic dissolution (central part of figure), then $50 \mathrm{keV}$ $B^{+}$ion implantation is performed followed by $\mathrm{Al}$ metallization on both sides of the n-type epitaxial thin silicon membrane (lower part of figure). 
The thin detector thickness pattern (with one mm steps in $X$ and $Y$ directions) was measured by transmission of $\alpha$ particles from a ${ }^{241} \mathrm{Am}\left(\left\langle E_{\alpha}\right\rangle=\right.$ $5.5 \mathrm{MeV})$ source using a PIN diode as a stop detector. The result is shown in Fig. 2 (a). The thickness distribution was calculated using range-energy tables of $\alpha$ particles in silicon. The average thickness resulting from the map of Fig. 2 (a) is $\approx 5 \mu \mathrm{m}$ and the nonuniformity is about $1 \mu \mathrm{m}$ over the four-inch wafer area. The thickness distribution has approximately a central symmetry. It is related to the method of the anodic dissolution process [2]. Four-inch silicon epitaxial $5 \mu \mathrm{m}$ strip detector shown in Fig. 2 (b) is glued into the PCB using a conductive epoxy resin hardening at $120^{\circ} \mathrm{Cel}-$ sius. After cooling at room temperature, the contraction of $\mathrm{PCB}$ produced wavy-shaped deformations of the thin silicon membrane. Each detector strip is electrically connected with PCB bonding pads by $25 \mu \mathrm{m} \mathrm{Al}$ wires using ultrasonic bonding.

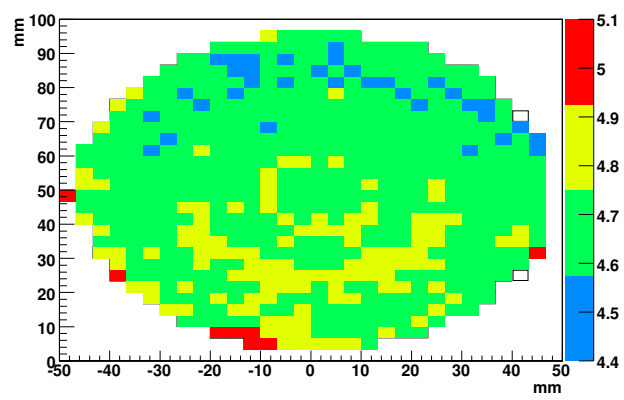

(a) Thickness distribution

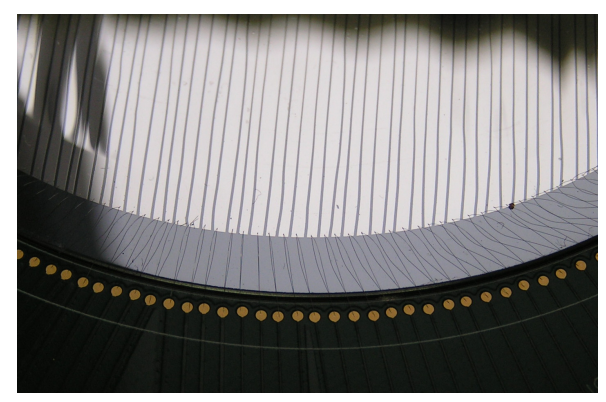

(b) Superthin strip detector

Fig. 2. (Color online) (a) Thickness distribution of the epitaxial thin silicon detector. Measurements have been performed using an $\alpha$ particle ${ }^{241} \mathrm{Am}$ source. Color scale is in $\mu \mathrm{m}$. (b) Superthin $\Delta E$ strip detector. Connections of about $1 \mathrm{~mm}$ wide strips with gold PCB bonding pads were performed using $25 \mu \mathrm{m} \mathrm{Al}$ wires.

\section{Test measurements of superthin, ion implanted strip detectors produced by low-temperature technique}

The thin $5 \mu \mathrm{m}$ strip detector was operated using internal electric builtin-field without any external bias (like solar cells). For tests, the $\Delta E-E$ telescope was formed using single strip $1 \mathrm{~mm}$ wide collimated to about one or two $\mathrm{mm}$ followed by $300 \mu \mathrm{m}$ thick $\mathrm{E}$ detector. Test measurements have been performed with $9 \mathrm{~mm}$ long strip. Response for $6.1 \mathrm{MeV} \alpha$ particles and fission fragments from ${ }^{252} \mathrm{Cf}$ is presented in Fig. 3. 


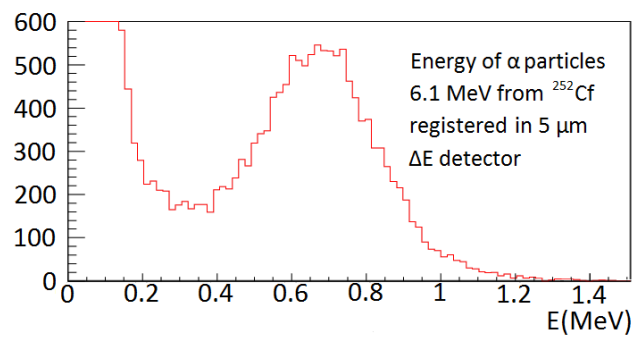

(a) Energy loss of $\alpha$ particles

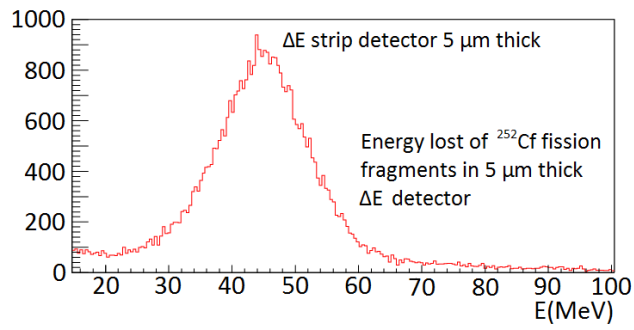

(c) Energy loss of fission fragments

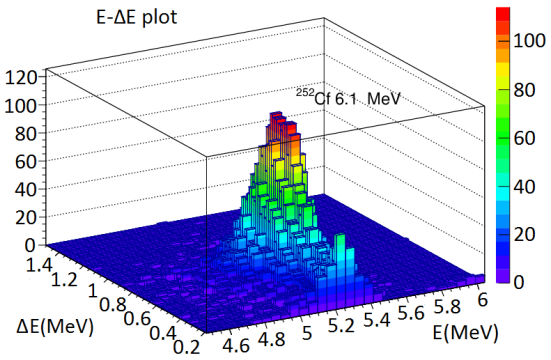

(b) $\Delta E-E$ plot of $\alpha$ particles

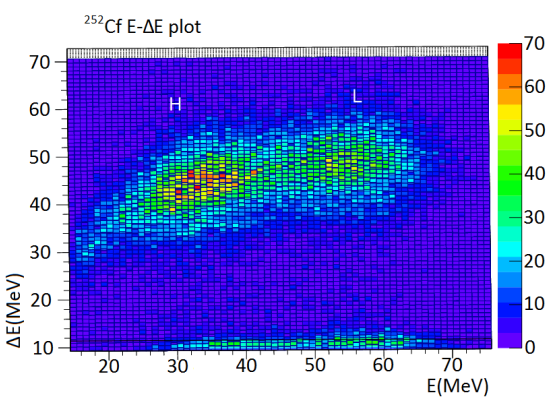

d) $\Delta E-E$ plot of fission fragments

Fig. 3. (Color online) (a) The energy loss of $6.1 \mathrm{MeV} \alpha$ particles in $5 \mu \mathrm{m}$ thick $\Delta E$ strip. (b) Response of the $\Delta E-E$ telescope with $5 \mu \mathrm{m} \Delta E$ strip for $6.1 \mathrm{MeV}$ $\alpha$ particles from ${ }^{252} \mathrm{Cf}$ source, color scale in counts. (c) The energy loss of fission fragments from ${ }^{252} \mathrm{Cf}$ in $5 \mu \mathrm{m}$ thick $\Delta E$ strip. (d) Response of the $\Delta E-E$ telescope consisting of $5 \mu \mathrm{m}$ strip followed by $300 \mu \mathrm{m}$ silicon detector for fission fragments from ${ }^{252} \mathrm{Cf}$. Color scale in counts.

\section{Results, conclusions and future applications}

In our measurements, we have tested one $5 \mu \mathrm{m}$ thick, $9 \mathrm{~mm}$ long and $1 \mathrm{~mm}$ wide strip operated using built-in-field without any external bias potential. The strip surface is $9 \mathrm{~mm}^{2}$. The capacitance of this strip is about $530 \mathrm{pF}$, however, the calculated silicon capacitor of dimensions $9 \mathrm{~mm} \times 1 \mathrm{~mm}$ $\times 5 \mu \mathrm{m}$ is about $200 \mathrm{pF}$. This suggests the existence of a dead layer of the back contact of about $2 \mu \mathrm{m}$. It may be caused by a finite border between the high-resistivity silicon epitaxial layer and the low-resistivity silicon substrate. This problem will be further investigated in future. The electronic noise of this strip measured by injection of charge through a calibrated capacitor is about $50 \mathrm{keV}$. The energy loss of $5 \mathrm{MeV}$ protons in $5 \mu \mathrm{m}$ thick silicon layer is about $70 \mathrm{keV}$. Therefore, a measurement of the energy loss of $5 \mathrm{MeV}$ protons in a thin $5 \mu \mathrm{m}$ thick silicon detector is possible, if electronic noise is at 
the level of about $20 \mathrm{keV}$. The reduction of electronic noise is possible for a selfbiased thin $5 \mu \mathrm{m}$ thick silicon detector by decreasing the detector capacitance, which can be achieved by reducing the strip width to about $0.1 \mathrm{~mm}$. Such a strip detector with strips of $20 \mathrm{~mm}$ long and 0.1 wide will be able to measure protons, light charged particles and heavy ions. The silicon vertex detector made of superthin silicon strip silicon detectors is proposed in Ref. [3]. It can be used for measurements of low-energy charged particles, heavy ions and superheavy elements with particle energy measurements and geometrical reconstruction of all particle tracks. The silicon vertex detector can be used to study $N$-particle correlations [4-6] to probe decay branching ratios for unbound states in the Brunnian nucleus ${ }^{10} \mathrm{C}$ and for the Hoyle state of ${ }^{12} \mathrm{C}$. Four-particles $p-p-\alpha-\alpha$ correlation functions probing the decay of unbound states in ${ }^{10} \mathrm{C}$, revealed the existence of four-body direct decay (DD) mechanisms and sequential decays (SD). These mechanisms proceed via production of intermediate unbound states of ${ }^{9} \mathrm{~B},{ }^{8} \mathrm{Be}$ and ${ }^{6} \mathrm{Be}$ nuclei [5]. Similarly three-alpha correlations showed that the Hoyle state in ${ }^{12} \mathrm{C}$ decays with both DD mechanism $\left({ }^{12} \mathrm{C} \rightarrow 3 \alpha\right)$ and SD mechanism $\left({ }^{12} \mathrm{C} \rightarrow \alpha+{ }^{8} \mathrm{Be}\right.$ followed by ${ }^{8} \mathrm{Be} \rightarrow 2 \alpha$ ) [5]. The decay mechanisms (DD and SD) of ${ }^{12} \mathrm{C}$ Hoyle states are investigated by Dalitz plots method [7].

The application of the silicon vertex detector made of superthin silicon strip detectors with reconstruction of all particle tracks will be a new method for investigation of decay branching ratios for unbound states, which is at the present day analysed by Dalitz plot [7] for the Hoyle state of ${ }^{12} \mathrm{C}$.

\section{REFERENCES}

[1] A.J. Kordyasz et al., Eur. Phys. J. A 51, 15 (2015).

[2] A.J. Kordyasz et al., Nucl. Instrum. Methods Phys. Rev. A 570, 336 (2007).

[3] A.J. Kordyasz et al., Conference Proceedings Vol. 105, International Workshop on Multifragmentation and Related Topics, J.D. Frankland, A. Pagano, S. Pieronne, M.F. Rivet, F. Riazzo (Eds.), SIF, Bologna 2012.

[4] R.J. Charity et al., Phys. Rev. C 52, 3126 (1995).

[5] F. Grenier et al., Nucl. Phys. A 811, 233 (2008).

[6] A. Raduta et al., Phys. Lett. B 705, 65 (2011).

[7] M. Itoh et al., Phys. Rev. Lett. 113, 102501 (2014). 